УДК 378.178

\author{
Соколовский Максим Леонидович
}

\title{
СОЦИОКУЛЬТУРНАЯ БЕЗОПАСНОСТЬ ОБРАЗОВАТЕЛЬНОЙ СРЕДЫ ВУЗА ${ }^{1}$
}

В статье излагается структура концепта сочиокультурной безопасности (СКБ) образовательной среды вуза, рассматриваются подходы к ее оченке с позиций современного состояния педагогической и психологической науки. Представлены и описаны основные компоненты СКБ: сохранность и развитие культуры; человеческое развитие в понимании ООН; жизнестойкость, понимаемая как в узком смысле (в качестве субъектности), так и в широком - как набор личностньхх и сочиальных факторов, позволяюших человеку преодолевать жсизнениые трудности, восстанавливать и продвигаться к достижсеню традицонных личных иееностей; компетентные действия властей и самих представителей этнокультур, что согласуется с локальными и мировыми тенденциями по формированию и сохранению культур этносов

Ключевые слова: сочиокультурная безопасность, сохранность и зацита культуры, человеческое развитие.

\section{Maksim Sokolovskii \\ SOCIOCULTURAL SAFETY CONCEPT IN EDUCATIONAL ENVIRONMENT OF UNIVERCITY}

The article describes the structure of the concept of sociocultural safety (SCS) of the educational environment of university, examines approaches to its assessment from the standpoint of the current state of the pedagogical and psychological sciences. The main components of the SCS are presented and described: preservation and development of culture; human development as understood by the UN; resilience, understood both in a narrow sense (as a subjectivity) and broadly, as a set of personal and social factors that enable a person to overcome life's difficulties, recover and move tow ards the achievement of traditional personal values; competent actions of the authorities and representatives of ethno cultures themselves, which is consistent with local and global trends in the formation and preservation of cultures of ethnic groups.

Key words: sociocultural safety, sociocultural safeness and security, human development.

Bведение / Introduction. Проблема социокультурной безопасности образовательной среды становится всё более актуальной как в глобальном - в рамках образовательной системы Российской Федерации, так и в локальных контекстах - на уровне образовательных учреждений и даже отдельных учебных групп в связи с многочисленными социокультурными угрозами, вызванными как межэтническими взаимодействиями [1], так и процессами глобализации, когда под угрозой может оказаться даже культура и психологическая безопасность доминирующих этносов [2].

В нашем исследовании мы использовали некоторые рабочие определения.

Социокультурная безопасность - это сохранность и развитие (этнической) культуры свободной (самостоятельной, активной, деятельной) личности в условиях культурно-компетентной окружающей среды.

Психологическая безопасность рассматривалась нами как сложный, многофакторный, во многом находящийся на стадии формирования предмет современных психолого-педагогических исследований, представляющий собой набор личностных и социальных характеристик, позволяющих субъекту образовательной среды сохранять целостность, развиваться, реализовывать собственные цели и ценности в процессе жизнедеятельности [4].

\footnotetext{
Работа выполнена при финансовой поддержке РФФИ, проект № 18-013-00832 «Влияние аккультурационных установок на социокультурную безопасность студентов»
} 
Культурно-компетентная окружающая среда - это система (ситуация и условия) профессионального или бытового взаимодействия, поддерживающая или формирующая уважение к личности, в том числе как к представителю данной этнической группы. При этом свободной подразумевается личность с развитой субъектностью при наличии возможностей социальной реализации своей субъектности.

Зарубежные специалисты при исследовании этнокультурных аспектов организации учебно-воспитательного процесса широко используют понятия sociocultural safety и sociocultural security, которые можно понимать как обеспечение сохранности и обеспечение охраны культуры учащихся.

При этом исследования сохранности этнической культуры в большей степени относятся к учащимся, выступающим в роли актуальных или потенциальных носителей собственной этнической культуры. В то же время обеспечение безопасности поддержания, формирования и развития культуры учащихся в наибольшей степени подразумевает действия педагогов, властей, значимых взрослых по обеспечению сохранности культуры или культурного разнообразия, т. e. security, или культурно-компетентную окружающую среду.

Pезультаты и обсуждение / Results and discussion. Опираясь на работы В. Станнера [13], а также Р. Франкланда, М. Бамблета и П. Льюиса [8], можно выделить определенную структуру сохранности и развития культуры в учебно-воспитательном процессе.

(1) Мотив. Субъекты культуры признают себя таковыми. Признают свою ценность как носителей культуры и ценность собственной культуры, чем получают внутренний стимул для воссоздания и развития собственной культуры.

(2) Свобода. У них есть достаточная свобода и самостоятельность (субъектность) реализовываться, действовать как представители данной культуры.

(3) Ресурсы. У них есть достаточно ресурсов для воспроизводства собственной культуры, и, конечно же, во многом эти ресурсы предоставляются родителями и педагогами

(4) Деятельность. Собственно культурная практика коренных народов, воспроизводство продуктов культуры

Данные компоненты сохранности культуры тесно взаимосвязаны между собой, в частности, для мотивации (1) и свободы, выражающейся в субъектности (2) культурной деятельности важно осознание ценности себя и своей культуры. В то же время признание себя представителем определенной культуры (1) имеет смысл, если это хоть как-то отражается в их деятельности (4).

Тем не менее в структуре социокультурной безопасности субъектность мы выделяем в отдельный блок, поскольку:

(a) субъъектность выступает важнейшим компонентом человеческого развития как такового (в понимании Организации объединенных наций) [12],

(б) с точки зрения организации работ по обеспечению социокультурной безопасности выделяют различную природу факторов безопасного развития подростков. В частности, родители и окружающая среда могут оказывать на них защитное влияние, создавая «тепличные условия», или же «продвигает» их, создавая условия для самостоятельности и развития [14]. Если перенести этот подход в сферу социокультурной безопасности учебного процесса, то именно развитие субъектности испытуемых укрепляет и «продвигает» поддержание и развитие их культуры, представляя собой «активную» защиту культуры, в то время как формирование культурно-компетентной окружающей среды (security) и сохранность (safety), и в некоторой мере развитие культуры представляют собой «пассивную» защиту культуры учащихся,

(в) именно на основе субъектности учащихся могут формироваться особенности совладающего поведения у обучающихся, принадлежащих к различным этнокультурам [5]. 
Тем не менее признание учащимся себя представителем определенной культуры всегда реализуется в практической деятельности, организации внеклассных мероприятий и досуга учащихся. Поэтому в целях диагностики компонентов социокультурной безопасности образовательной среды целесообразно объединить мотивацию культурной деятельности и саму культурную деятельность в одну шкалу «Этнокультурная установка».

Поэтому блок сохранности культуры мы рассматривали как состоящий из двух основных компонентов (рис.):

(a) этническая идентичность и воссоздание продуктов культуры,

(б) наличие ресурсов для этнокультурной деятельности.

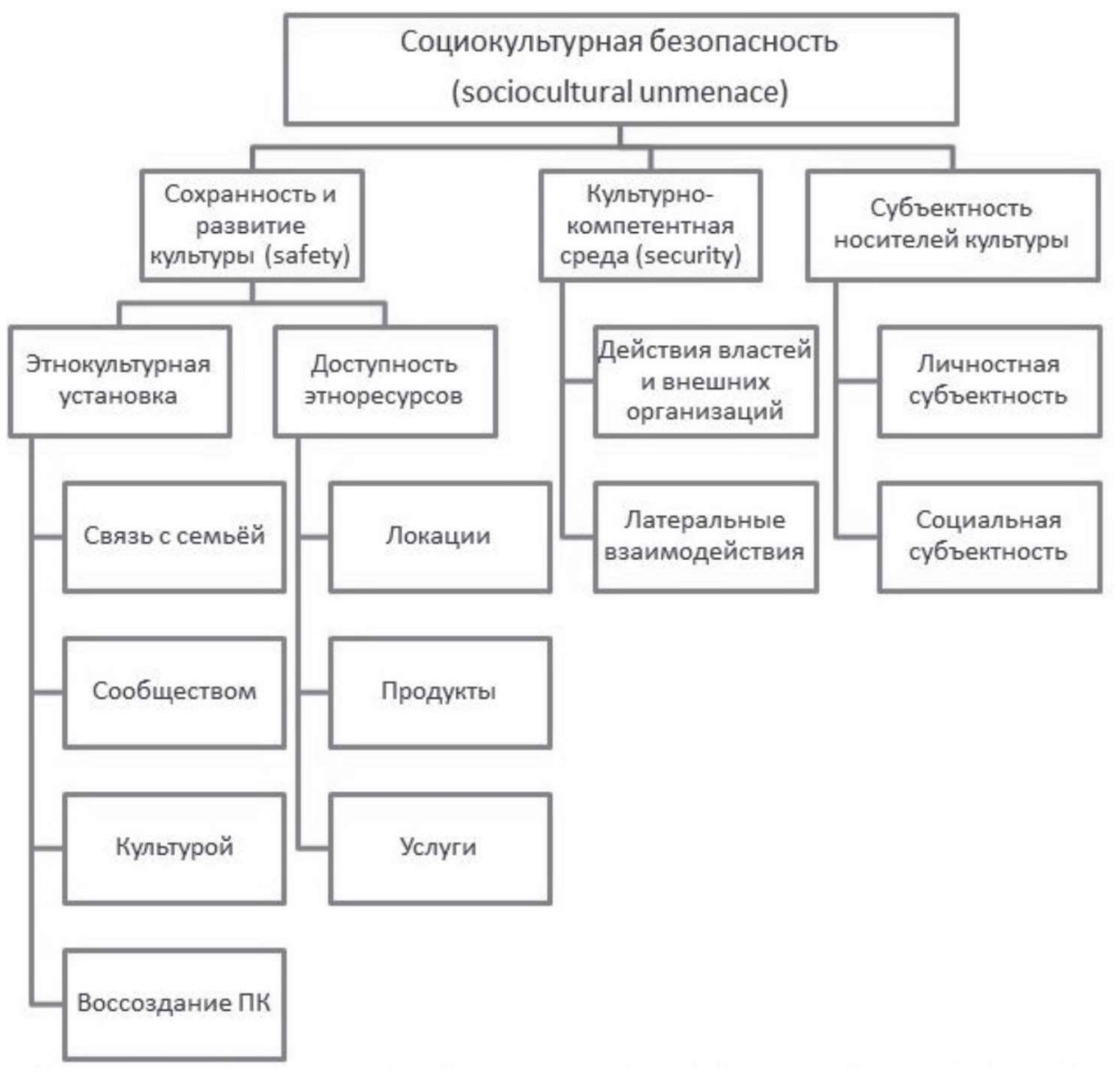

Рис. Модель социокультурной безопасности в организации учебного процесса

Безопасность (security) представляет собой такое состояние общества или его отдельных этнокультурных, социальных образований, учебных групп, при котором люди чувствуют свою защищенность и ценность как членов местного сообщества, могут решать вопросы безопасности, используя местные и государственные структуры, и желают взаимодействовать с ними [7]. В учебном процессе такая безопасность формируется за счёт взаимодействия двух компонентов:

a) культурно-компетентных действий значимых взрослых, педагогов и администрации вуза (культурная и этнокультурная компетентность при взаимодействии «по вертикали»),

б) взаимодействий между самими обучающимися, которые также должны носить характер культурной компетентности и исключать не только агрессию как таковую, но и конфликты в связи с этническими особенностями обучающихся. (культурная компе- 
тентность при взаимодействии «по горизонтали», или латеральные взаимодействия). Систематические унижения по этническому принципу могут привести к глобальному падению самооценки учащегося и формированию у него маргинализационной установки, являющейся серьёзным препятствием в его дальнейшем развитии

Самостоятельность, или субъектность учащегося, будучи важным компонентом социокультурной и психологической безопасности активно изучается в отечественной психологии начиная с 70-х годов прошлого века О. А. Конопкиным [3] и его многочисленными учениками и является важным компонентом работы Организации Объединенных наций.

В докладе ООН за 2016 год субъектность представлена как один из ключевых элементов человеческого развития. При этом в качестве основных компонентов субъектности ООН рассматривает право голоса обучающегося как возможность быть услышанным и влиять на происходящее (voice), так и собственно желание и возможность самостоятельно совершать активные действия (agency) [7], то есть в субъектности выделяется личностный и социальный компоненты.

Эти составляющие субъектности крайне важны в образовательном процессе. Для успешного развития студенту важно уметь формулировать и достигать собственные цели и при необходимости противостоять давлению окружающих. В то же время достижение собственных целей, как правило, требует не только умения взаимодействовать с другими людьми (развития эмоционального интеллекта), но и формирования определённых организаторских навыков. В частности, М. Бамблетт и др. «право голоса» (voice) понимают как самоопределение, связанное с тем, как желания и проблемы, например, этнических меньшинств, выражаются и оказывают влияние на доминантную культуру (социальный компонент). В то время как «жизнестойкость» (resilience) ими рассматривается как эмпатия, позитивный взгляд на мир, чувство юмора, хорошие взаимоотношения и выраженное ощущение собственной культурной принадлежности (личностный компонент субъектности) [6].

Мы также выделяем личностный и социальный компоненты субъектности. Под личностным компонентом субъектности мы понимаем жизнестойкость учащихся (resilience) в узком смысле как активность в преодолении жизненных и образовательных трудностей в тех случаях, когда можно хотя бы в некоторой степени абстрагироваться от социального компонента субъьектности. Если же достижение собственных целей личности требует социального взаимодействия, а именно, определяется откликом, полученным от других людей, то мы говорим о социальном компоненте субъектности. Например, вопрос «С целью улучшения оценки я выполняю дополнительные задания» может рассматриваться как личностная субъектность в образовательной сфере, так как здесь, в терминологии Михаила Голля, присутствует намеренное увеличение объема работы как одно из проявлений субъектности на рабочем месте [9]. Для достижения таких самостоятельно поставленных учебных задач учащийся может не обращаться за помощью к сверстникам или значимым взрослым.

В то же время утверждение «Я спрашиваю учителя, какие дополнительные задания я могу выполнить, чтобы улучшить оценку» - это социальная субъъектность, поскольку непосредственно направлена на другого человека, с которым нужно договориться.

Концепция Бамблетта и др. в целом согласуется с разработанной М. Голлем структурой субъектности на рабочем месте, в которой, как и в учебном процессе, можно выделить: личностную составляющую субъектности, субъектные трудовые (учебные) действия и организационные факторы субъектности.

Поскольку все компоненты социокультурной безопасности образовательного процесса и формирования учащегося как самостоятельной, деятельной, социально активной и успешно обучающейся личности тесно связаны между собой, эффективная коррекция одного из компонентов социокультурной безопасности подразумевает работу или отклик со стороны других ее компонентов. Поэтому расширенная модель субъектности, помимо личностного, задействует и межличностный и организационный компоненты [9]. 
Весьма перспективной и во многом концептуально сходной с нашей моделью социокультурной безопасности образовательного процесса является диагностическая и коррекционная модель жизнестойкости детей, молодёжи и взрослых (CYRM / ARM), активно разрабатываемая под руководством Майкла Ангара с середины 2000-х годов и внедренная в практическую деятельность по коррекционной работе с трудными подростками, малыми народами, в воспитательный процесс многих общеобразовательных школ. Майкл Ангар жизнестойкость (resilience) понимает в очень широком смысле, сопоставимо предложенной нами моделью социокультурной безопасности.

С точки зрения М. Ангара, жизнестойкость актуализируется в ситуации, когда личность испытывает серьезные лишения, и проявляется, во-первых в способности личности, или даже целых сообшеств, двигаться к тем ресурсам, которых они лишены; во-вторых в способности договариваться с другими людьми по вопросам возможности достижения необходимых ценностей или ресурсов. Поэтому, в-третьих, работа психологов, социальных работников, других социально-культурных служб представляет собой создание таких структур или ресурсов, которые будут способствовать самостоятельному достижению индивидом личных или социокультурных ценностей [10], то есть обеспечивать общее человеческое развитие личности.

Структура разрабатываемых М. Ангаром и его коллегами опросников по изучению жизнестойкости, соответственно, включает в себя три шкалы с субшкалами: личностные характеристики (личные навыки жизнестойкости, поддержка со стороны сверстников, социальные навыки), отношения с семьёй (физическая забота, психологическая поддержка), оценка испытуемым среды (духовной, образовательной, культурной) [11]

Тем не менее есть ряд концептуальных и структурных отличий подхода М. Ангара и его коллег от нашей модели. Изначально модель М. Ангара является корректирующей, а не развивающей, и предполагает наличия неких фрустрирующих обстоятельств, актуализирующих жизнестойкость обучающихся. Мы больший акцент делаем на возможность социокультурного развития студентов в условиях развитой, компетентностной, психологически безопасной социокультурной среды вуза.

Заключение / Conclusion. Таким образом, наша модель социокультурной безопасности концептуально опирается на четыре ключевых, взаимосвязанных и взаимопересекающихся компонента:

1) сохранность и развитие культуры,

2) человеческое развитие в условиях психологической безопасности;

3) жизнестойкость, понимаемая как в узком смысле (в качестве суббъектности), так и в широком - как набор личностных и социальных факторов, позволяющих человеку преодолевать жизненные трудности, восстанавливаться и продвигаться к достижению традиционных личных ценностей (в сфере семьи, работы, материального благополучия),

4) компетентные действия властей и самих представителей этнокультур, что согласуется с локальными и мировыми тенденциями развития образования в поликультурной образовательной среде.

В рамках практического внедрения данного подхода нами разработан опросник СКБ (социокультурной безопасности), состоящий из 6 субшкал: этническая идентичность и воссоздание продуктов культуры, доступность этнокультурных ресурсов, личностная субъектность, социальная субъектность, латеральные взаимодействия, действия властей и внешних организаций, который прошел апробацию на базе Северо-Кавказского федерального университета.

\section{ЛИТЕРАТУРА И ИНТЕРНЕТ-РЕСУРСЫ}

1. Банщикова Т. Н. Кросс-культурный подход в системе методологических подходов к исследованию проблемы психической регуляции // Материалы V Международной научно-практической конференции «Личностный ресурс субъекта труда в изменяющейся России». Часть 1. Пятигорск: Научный мир, 2018. С. 39-45. 
2. Зинченко Ю. П. Методологические проблемы психологии безопасности. Личность, общество, государство: монография. М.: МГУ, 2011. 952 с.

3. Конопкин О. А. Психическая саморегуляция произвольной активности человека (структурно-функциональный аспект) // Вопросы психологии. 1995. № 1. С. 5-12.

4. Молокоедов А. В., Слободчиков И. М., Франц С. В. Психологическая безопасность личности: основы комплексного анализа. М.: Левъ, 2017. 176 с.

5. Соломонов В. А., Фомина Е. А. Совладающее поведение иностранных студентов: социокультурный аспект // Материалы V Международной научно-практической конференции «Личностный ресурс субъекта труда в изменяющейся России». Пятигорск: Научный мир, 2018. С. 239-246.

6. Bamblett M., Harrison J., \& Lewis P. Proving culture and voice works: Towards creating the evidence base for resilient Aboriginal and Torres Strait Islander children in Australia // International Journal of Child and Family Welfare. 2010. № 13 (1-2). C. 98-113.

7. Bennett W. Community Security handbook. London: Saferworld. Retrieved, 2014. URL: www.saferworld. org.uk.

8. Frankland R., Bamblett M., \& Lewis P. Forever Business: A Framework for Maintaining and Restoring Cultural Safety in Aboriginal Victoria // Indigenous Law Bulletin. 2011. June 7(24). P. 27-30.

9. Goller M. Human Agency at Work: An Active Approach towards Expertise Development (1st ed.). Wiesbaden, Germany: Springer VS, 2017.

10. UngarM. The socialecology of resilience:Addressing contextualand cultural ambiguity of anascentconstruct// American Journal of Orthopsychiatry. 2011. № 81(1). P. 1-17. URL: https:/ 10.1177/1049731511428619/ doi.org/10/ck342n.

11. Liebenberg L., Ungar M., Vijver F. V. de. Validation of the Child and Youth Resilience Measure-28 (CYRM28) Among Canadian Youth // Research on Social Work Practice. 2012. Vol. 22, № 2. P. 219-226.

12. United Nations Development Programme. Human Development Report 2016: Human Development for Everyone. 2017. UN. URL: https://doi.org/10.18356/b6186701-en.

13. William Stanner. The Dreaming \& Other Essays. Black Inc. Agenda. 2011.

14. Wright M., \& Masten A. Pathways to Resilience in Context. In Youth resilience and culture: commonalities and complexities New York: Springer, 2014. P. 3-22.

\section{REFERENCES AND INTERNET RESOURCES}

1. Banshchikova T. N. Kross-kulturnyj podhod $\mathrm{v}$ sisteme metodologicheskih podhodov kissledovaniyu problem psihicheskoj regulyacii (Cross-cultural approach in the system methodological approaches to research of the problem of mental regulation) // Proceedings of the V international conference «Personal resourse of human agency at work in changing Russia». Part 1. Pyatigorsk, 2018. S. 39-45. URL: http:// doi.org/10.30888/978-5-6041451-4-2.1.5

2. Zinchenko Yu. P. Metodologicheskie problemy psihologii bezopasnosti. Lichnost', obshchestvo, gosudarstvo (Methodological problems of security psychology. Personality, society, state: monografiya. M.: MGU, 2011. VA. 952 p.

3. Konopkin O. A. Psihicheskaya samoregulyaciya proizvolnoj aktivnosti cheloveka (strukturno funkcionalnyj aspect) (Mental self-regulation of arbitrary activity of a person (structural and functional aspect)) // Psychological issues. 1995. № 1. S. 5-12.

4. Molokoedov A. V., Slobodchikov I. M., Franc S. V. Psihologicheskaya bezopasnost' lichnosti: osnovy kompleksnogo analiza (Psychological security of personality: fundamentals of complex analysis). M.: Lev, 2017. $176 \mathrm{~s}$.

5. Fomina E. A., Solomonov V. A. Sovladayushchee povedenie inostrannyh student sociokulturnyj aspekt (Features of coping behavior of international students: sociocultural aspect) // Proceedings of the V International conference «Personal resourse of human agency at work in changing Russia». Part 1. Pyatigorsk, 2018, S. 39-45. URL: http://doi.org/10.30888/978-5-6041451-4-2.1.34

6. Bamblett M., Harrison J., \& Lewis P. Proving culture and voice works: Towards creating the evidence base for resilient Aboriginal and Torres Strait Islander children in Australia // International Journal of Child and Family Welfare. 2010. № 13 (1-2). P. 98-113. 
7. Bennett W. Community Security handbook. London: Saferworld. Retrieved, 2014. URL: www.saferworld. org.uk.

8. Frankland R., Bamblett M., \& Lewis P. Forever Business: A Framework for Maintaining and Restoring Cultural Safety in Aboriginal Victoria // Indigenous Law Bulletin. 2011. June 7(24). P. 27-30.

9. Goller M. Human Agency at Work: An Active Approach towards Expertise Development (1st ed.). Wiesbaden, Germany: Springer VS, 2017.

10. Ungar M. The social ecology of resilience: Addressing contextual and cultural ambiguity of a nascent construct // American Journal of Orthopsychiatry. 2011. № 81(1). P. 1-17. URL: https://doi.org/10/ck342n.

11. Liebenberg L., Ungar M., Vijver F. V. de. Validation of the Child and Youth Resilience Measure-28 (CYRM28) Among Canadian Youth // Research on Social Work Practice. 2012. Vol. 22, № 2. P. 219-226.

12. United Nations Development Programme. Human Development Report 2016: Human Development for Everyone. 2017. UN. URL: https://doi.org/10.18356/b6186701-en.

13. William Stanner. The Dreaming \& Other Essays. Black Inc. Agenda, 2011.

14. Wright M., \& Masten, A. Pathways to Resilience in Context. In Youth resilience and culture: commonalities and complexities. New York: Springer, 2014. P. 3-22

\section{СВЕДЕНИЯ ОБ АВТОРЕ}

Соколовский Максим Леонидович, кандидат психологических наук, ведущий научный сотрудник научно-образовательного центра психологического сопровождения личностно-профессионального развития Института образования и социальных наук, Северо-Кавказский федеральный университет. E-mail: bilb2000@yandex.ru

\section{INFORMATION ABOUT AUTHOR}

Maksim Sokolovskii, PhD equivalent, pedagogical psychology, Leading Researcher of the Scientific and Educational Center for Psychological Support of Personality and Professional Development, Institute of Education and Social Sciences, North-Caucasus Federal University. E-mail: bilb2000@yandex.ru 